\title{
Evaluation of Flexural Strength of Autopolymerizing Polymethyl Methacrylate and Bis-acrylic Composite Provisional Restorative Resins Reinforced with Bamboo Fibers: An In Vitro Study
}

\author{
Keerthika Natarajan ${ }^{1}$, Suganya Srinivasan ${ }^{2}$, Murugesan Krishnan ${ }^{3}$, Muthukumar Balasubramanian ${ }^{4}$
}

\begin{abstract}
Aim and objective: The aim is to reinforce autopolymerizing polymethyl methacrylate (PMMA) and bis-acrylic composite (BAC) provisional restorative resin with bamboo fibers and evaluate its effect on the flexural strength of the resin in comparison to the unreinforced material. The objective of the study is to find a suitable natural alternative to synthetic fibers like glass to strengthen the materials used for fabricating provisional fixed partial dentures.

Materials and methods: A total of 4 groups each containing 15 samples of $25 \times 2 \times 2 \mathrm{~mm}$ dimension namely group I: unreinforced PMMA, group II: PMMA resin reinforced with bamboo fibers, group III: unreinforced BAC and group IV: BAC resin reinforced with bamboo fibers. The bamboo fibers of $22 \mathrm{~mm}$ length were initially pretreated with $6 \%$ Sodium hydroxide solution for 12 hours and dried thoroughly for 2 weeks. The dried fibers were placed longitudinally in the reinforced samples by a layering method at $5 \% \mathrm{w} / \mathrm{w}$ concentration. For determining the flexural strength, specimens were then tested by 3-point bend test on universal testing machine. The fractured samples were then analyzed using scanning electron microscope at 50x, 100x, 250x magnification.

Results: The results obtained were analyzed in STATA software release 14.0 using one-way ANOVA test. According to the results, the mean flexural strength (in MPa) values were group IV (152.42) > group II (127.2) > group III (106.79) > group I (99.28) and was statistically significant $p=0.001$. Conclusion:Thus, bamboo fibers have a reinforcing effect on autopolymerizing polymethyl methacrylate and bis-acrylic composite provisional restorative resins and significantly increases their flexural strength.

Keywords: Dental materials, Natural fibers, Temporary restoration, Three point bending test.

International Journal of Prosthodontics and Restorative Dentistry (2021): 10.5005/jp-journals-10019-1320
\end{abstract}

\section{INTRODUCTION}

Provisional restorations are provided to substitute the definitive restoration during the interval between tooth preparation and the placement of the definitive restoration. These restorations are also referred to as interim or temporary restorations. ${ }^{1}$ They are used to protect the prepared tooth both biologically and biomechanically. Provisional restorations should be the same as definitive restorations in all aspects, except for the material from which they are fabricated. ${ }^{2}$

Occasionally, interim prosthesis has to function for extended intervals and provide long-term tooth protection and stability while adjunctive treatment is accomplished. Furthermore, long-term interim prostheses require materials that are more durable because of their longer periods of service. Flexural strength of a material is the ability by virtue of which it can oppose deformation likely to be imparted to it under application of load. The flexural strength of interim prostheses is a critical property, in case of long span fixed partial dentures and when the patient exhibits parafunctional habits such as bruxism and clenching. Flexural strength is also important when these restorations are worn over a long period of time to assess the results of periodontal, endodontic, and temporomandibular joint dysfunction therapies and during the restorative phase of implant reconstructive procedures. ${ }^{3}$

Materials commonly used to fabricate provisional restorations are autopolymerizing polymethyl methacrylate (PMMA) resin and bis-acrylic composite (BAC) resin. ${ }^{4}$ The most common problem
${ }^{1-4}$ Department of Prosthodontics, SRM Dental College, Chennai, Tamil Nadu, India

Corresponding Author: Keerthika Natarajan, Department of Prosthodontics, SRM Dental College, Chennai, Tamil Nadu, India, Phone: +91 7358272321, e-mail: drkeerthikanatarajan@gmail.com

How to cite this article: Natarajan K, Srinivasan S, Krishnan M, et al. Evaluation of Flexural Strength of Autopolymerizing Polymethyl Methacrylate and Bis-acrylic Composite Provisional Restorative Resins Reinforced with Bamboo Fibers: An In Vitro Study. Int J Prosthodont Restor Dent 2021;11(3):112-118.

Source of support: Nil

Conflict of interest: None

with interim fixed partial denture fabricated from these materials is fracture, and hence these materials alone cannot be used for longterm provisional restorations. ${ }^{5}$ Although sufficient improvements in materials and their properties have been obtained, it is still desired to derive a more ideal material with increased strength and improved esthetics that is amenable to long-term provisional usage. ${ }^{6}$

Several methods and materials have been attempted to reinforce these provisional restorative resins such as use of a stainless steel wire, cast metal on lingual side, a processed acrylic resin and fibers. Various fibers that are used are glass, polyethylene, 
carbon and quartz. However, these fibers are non-degradable, and their mode of disposal at the end of life is unknown. Based on the importance of the environment and the threat of climate change, researchers are interested in substituting natural fibers for synthetic fibers. Various natural fibers obtained from plants like sisal, hemp, flax and bamboo have been gaining importance as a reinforcement material in the material sciences with immense research being done on these materials. ${ }^{7}$

Presently, bamboo is being considered as an important plant fiber and its utilization as reinforcements in composites and polymers have increased tremendously. ${ }^{8}$ Due to its importance and abundant availability, many studies have been aimed at the anatomical structure, chemical composition and various mechanical properties to be able to utilize the material to its full potential. ${ }^{9}$ Bamboo fiber is extracted from the bamboo culms using various mechanical and chemical methods. Based on its specific properties such as low density, specific strength, and stiffness, bamboo fiber can be compared with glass fibers. The use of bamboo fibers as a reinforcement material in polymers and composites used in construction materials, automotive parts and textile industry have distinctly improved the mechanical properties like tensile strength and flexural strength. ${ }^{10,11}$ The use of bamboo fiber as a reinforcement in dental materials and especially in provisional restorative resins have not been attempted. The potential of this material is yet to be explored in the field of dentistry and offers a lot of scope.

Thus, through this study we attempt to reinforce polymethyl methacrylate and bis-acrylic composite provisional restorative resin with bamboo fibers and evaluate the effect on the flexural strength of the resin in comparison to the unreinforced material.

\section{Materials and Methods}

The study was conducted at Department of Prosthodontics, SRM Dental College, Ramapuram, Chennai and Central Institute of Petrochemicals Engineering and Technology, Guindy, Chennai from June 2017 to June 2018. The study was approved by the institutional review board (SRMDC/IRB/2015/MDS/No.201).

\section{Preparation of Unreinforced Samples}

The samples of dimensions $25 \times 2 \times 2 \mathrm{~mm}$ were fabricated using a stainless-steel mold (Fig. 1) according to ISO (International

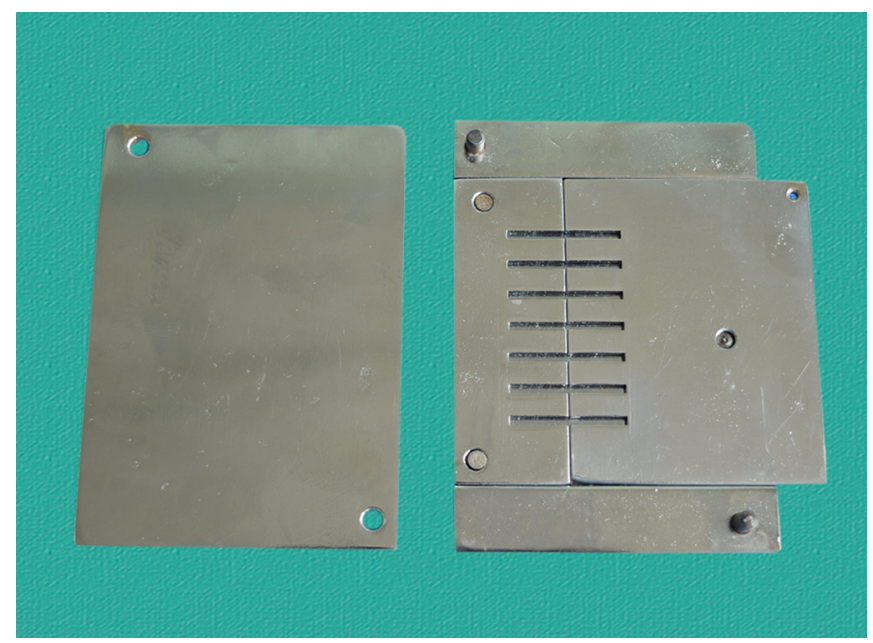

Fig. 1: Stainless steel mould
Organization for Standardization) standards given for polymerbased crown and bridge materials (ISO 10477:2004). The materials were manipulated based on the mixing ratio as mentioned by the manufacturers (Table 1).

\section{Treatment of Bamboo Fibers}

Bamboo (Bambusa balcooa) fibers were procured in the dried form from Tripura Natural Fibers and Bamboo Ltd (Agartala, Tripura) and soaked in $6 \mathrm{wt} \%$ sodium hydroxide $(\mathrm{NaOH})$ solution for 12 hours to remove greasy material and lignin from the fibers. The fibers were washed thoroughly in distilled water and dried under the sun for 2 weeks. The dry fibers were then cut into uniform lengths of $22 \mathrm{~mm}$ and soaked in monomer for 10 minutes in a Petri dish for improved adhesion of the bamboo fibers with PMMA resin matrix. The fibers were removed from the monomer and excess liquid was allowed to air dry for 5 minutes. For incorporating the fibers in $B A C$ resin specimens, bonding agent (AdperTM; 3M ESPE, Germany) were applied to the fibers and cured for 40 seconds with a halogen light cure unit (Megalux, Germany).

\section{Preparation of Bamboo Fiber Reinforced Samples}

The reinforced samples were prepared by the layering method (Fig. 2). The fibers were weighed and added to the reinforced samples in the ratio of $5 \% \mathrm{w} / \mathrm{w}$ of the unreinforced sample. The monomer and polymer of the PMMA material and the base and

Table 1: Materials used

\begin{tabular}{|c|c|c|c|c|}
\hline Material & Brand & $\begin{array}{l}\text { Manufac- } \\
\text { turer }\end{array}$ & Available as & Lot no. \\
\hline \multirow[t]{2}{*}{$\begin{array}{l}\text { Polym- } \\
\text { ethyl meth- } \\
\text { acrylate }\end{array}$} & $\begin{array}{l}\text { Powder: } \\
\text { DPI_RR }\end{array}$ & $\begin{array}{l}\text { Dental } \\
\text { Products } \\
\text { of India, } \\
\text { Mumbai, } \\
\text { India }\end{array}$ & $\begin{array}{l}\text { Powder and } \\
\text { liquid }\end{array}$ & (P) 5563 \\
\hline & $\begin{array}{l}\text { Liquid: DPI } \\
\text { self-cure, } \\
\text { tooth } \\
\text { moulding } \\
\text { powder for } \\
\text { crown and } \\
\text { bridgework } \\
\text { and tooth } \\
\text { reproduc- } \\
\text { tion }\end{array}$ & & $\begin{array}{l}\text { Mixing } \\
\text { ratio: 3:1 }\end{array}$ & (L) 2135 \\
\hline \multirow[t]{2}{*}{$\begin{array}{l}\text { Bis-acrylic } \\
\text { composite } \\
\text { resin }\end{array}$} & Protemp 4 & $\begin{array}{l}\text { 3M ESPE, } \\
\text { Neuss, } \\
\text { Germany }\end{array}$ & $\begin{array}{l}\text { Base and } \\
\text { catalyst } \\
\text { paste in } \\
\text { auto mixing } \\
\text { cartridge }\end{array}$ & (B) 619434 \\
\hline & & & $\begin{array}{l}\text { Mixing } \\
\text { ratio: 10:1 }\end{array}$ & (C) 617650 \\
\hline $\begin{array}{l}\text { Bonding } \\
\text { agent }\end{array}$ & $\begin{array}{l}\text { Adper Sin- } \\
\text { gle bond } 2\end{array}$ & $\begin{array}{l}\text { 3M ESPE, } \\
\text { Neuss, } \\
\text { Germany, }\end{array}$ & $\begin{array}{l}\text { Liquid with } \\
\text { applicator } \\
\text { tip }\end{array}$ & N828945 \\
\hline
\end{tabular}

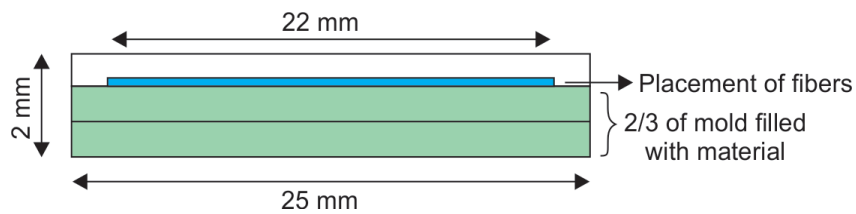

Fig. 2: Diagram representing sample preparation 
catalyst from the auto mixed syringe for BAC resin were filled until the mold was two-thirds full. The dried fibers were then placed on the mold and the remainder of the mold was then filled, covered with a glass plate and allowed to polymerize under an even pressure of 20 psi for 15 minutes. Fifteen minutes after polymerization, the samples were removed and any flash present was gently removed by gently abrading with abrasive paper $\left(3 \mathrm{M}^{\mathrm{TM}}\right.$ Wet or dry papersheets) between P220 and P320. The samples were then stored in distilled water $(\mathrm{pH}=5.9)$ at a set temperature of $(37 \pm 1)$ ${ }^{\circ} \mathrm{C}$ in an incubator for 24 hours prior to start of testing.

\section{Analysis of Samples}

The groups were divided as-group I: unreinforced PMMA, group II: PMMA resin reinforced with bamboo fibers, group III: unreinforced BAC, and group IV: BAC resin reinforced with bamboo fibers each containing 15 samples (Fig. 3A). For determining the flexural strength, the samples were tested by a three point bend test on universal testing machine (Instron Corp. No.3381). The $10 \mathrm{kN}$ load cell was applied at a cross-head speed of $(1 \pm 0.3) \mathrm{mm} /$ minute until the specimen fractured (Fig. 3B).

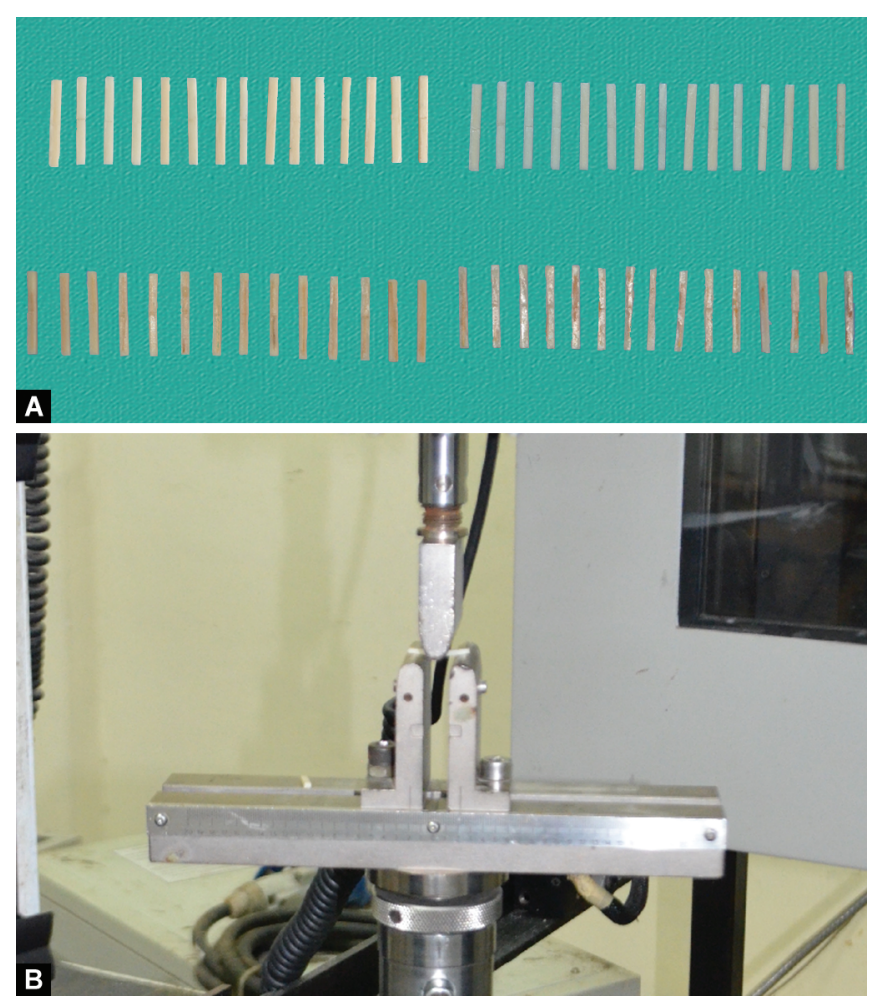

Figs 3A and B: (A) Samples; (B) Testing for flexural strength
Failure was marked by a perceptible crack and reconfirmed by the abrupt decrease in the recorded load-deflection curve and the corresponding unit of force was recorded. The calculated values of flexural strength in megapascals (MPa) were immediately displayed in the computer software of the testing machine (Supplementary Fig. 1). The software uses the equation: $\left[3 F L / 2 b d^{2}\right]$ to calculate the flexural strength $(\sigma B)$ in megapascals; where $F$ is the maximum applied load in Newtons $(\mathrm{N}) ; L$ is the distance between the supports in millimeters $(\mathrm{mm})$ i.e., $10 \mathrm{~mm}, b$ is the width of the test specimen in $\mathrm{mm}$; $h$ is the height of the test specimen in $\mathrm{mm}$ (Supplementary Table 1). The fractured samples were then analyzed using a scanning electron microscope (Zeiss EVO 18) under 50x, 100x, and 250x magnification.

\section{Results}

The results obtained were analyzed using STATA statistical software package release 14.0. A one-way ANOVA test was performed to compare the means across multilevel variables (Table 2). According to the results, the highest mean flexural strength value was seen in the samples of BAC resin reinforced with bamboo fibers (group IV), and the lowest mean flexural strength value was seen in unreinforced PMMA samples (group I) (Fig. 4). The mean flexural strength (in MPa) values obtained were group IV (152.42) > group II (127.2) > group III (106.79) > group I (99.28). The $p$ value obtained was $<0.05$ which means the values are statistically significant. The reinforced samples showed a higher value compared to the unreinforced samples. Among the reinforced samples highest flexural strength was shown by BAC resin reinforced with bamboo

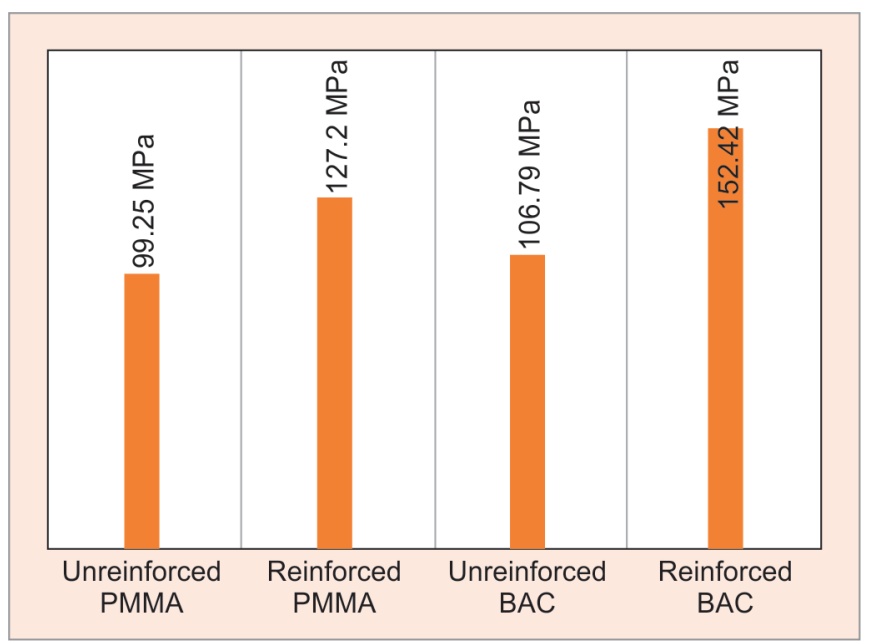

Fig. 4: Graph representing mean flexural strength of all groups

Table 2: One way ANOVA of the mean flexural strength (in megapascals-MPa)

\begin{tabular}{|c|c|c|c|c|c|}
\hline Group & $N$ & $\begin{array}{l}\text { Mean flexural strength } \\
(\mathrm{MPa})\end{array}$ & Standard deviation & Fvalue & pvalue \\
\hline I: Unreinforced PMMA & 15 & 99.28 & 16.17 & 10.52 & $p=0.001$ \\
\hline II: Reinforced PMMA & 15 & 127.20 & 43.28 & & \\
\hline III: Unreinforced BAC & 15 & 106.79 & 12.58 & & \\
\hline IV: Reinforced BAC & 15 & 152.42 & 30.57 & & \\
\hline
\end{tabular}



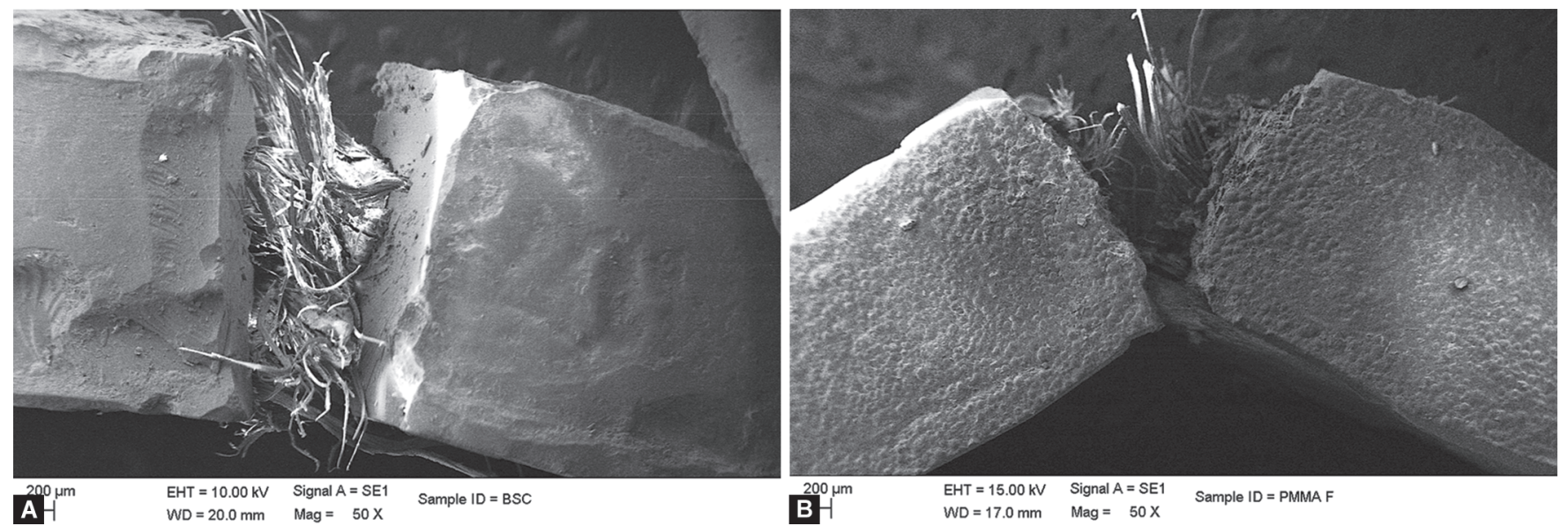

Figs 5A and B: (A) SEM images at 50× BAC; (B) SEM Images at 50× PMMA reinforced samples
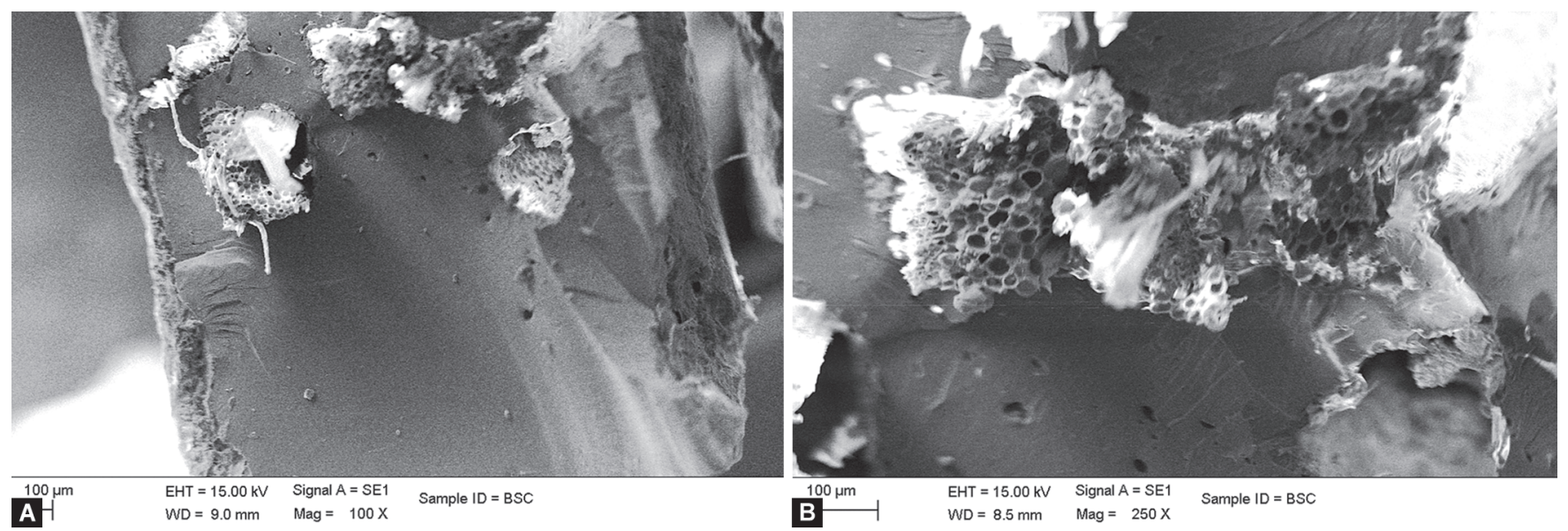

Figs 6A and B: (A) SEM image of fractured BAC reinforced sample at 100x; (B) SEM image of fractured BAC reinforced sample at 250X

fibers. Among the unreinforced samples, the highest flexural strength was shown by unreinforced BAC resin.

\section{SEM Analysis of Samples}

The $50 x$ magnification of the fracture site of the samples of bamboo fiber reinforced BAC (Fig. 5A) and PMMA (Fig. 5B) show the fibers resisting the fracture of the sample into separate pieces. The crosssection of the fractured sample of BAC at $100 \times$ (Fig. 6A) and 250 $\times$ (Fig. $6 \mathrm{~B}$ ) shows the integration of the bamboo fibers with the polymer material. The microstructure of the bamboo fibers is visible with vascular bundles and hollow parenchymal cells.

\section{Discussion}

Reinforcement with fibers is an effective method to increase the flexural strength and fracture toughness of provisional restorative resin. $^{12}$

Among the synthetic fibers; glass, carbon and polyethylene fibers have shown considerable success in reinforcement of the provisional restorative material. ${ }^{13,14}$ However, these synthetic fibers are considered to be non-biodegradable and thus can cause an ecological concern in the long run. Among the natural fibers, bamboo fibers have a unique structural anatomy that provides high stiffness and low weight that make it a highly competitive material for reinforcement of polymer composites. ${ }^{15}$

Bamboo is found in abundance in Asia and South America. Bamboo fibers have attracted broad attention as reinforcement materials as they are lighter, fast growing, renewable and can be compared with glass fibers in terms of mechanical properties. ${ }^{16}$ Several forms of bamboo can be used for reinforcement such as whole bamboo, sections, strips, and fibers. Bamboo fibers have been used as reinforcement with various thermoplastic and thermoset polymers.

The present study was conducted with the purpose of evaluating the flexural strength of autopolymerizing PMMA and $B A C$ resin material reinforced with bamboo fibers.

The mechanical properties of bamboo fiber reinforced composites depend on factors like interfacial adhesion of the matrix and fibers, fiber length, and fiber orientation. ${ }^{17}$

Successful application of natural fiber-reinforced composites is often limited by the interaction between the hydrophilic fibers and hydrophobic matrices. Pretreatment of the natural fibers helps improve the interfacial bonding and wettability of the fibers. The bamboo fibers are covered by organic matter mainly Cellulose, Hemicellulose and Lignin which render it a smooth surface. Soaking the fibers in an alkaline solution such as Sodium 
Hydroxide $(\mathrm{NaOH})$ helps in the removal of the organic content as well as other impurities. ${ }^{18}$

In this study, the bamboo fibers were treated with $6 \mathrm{wt} \% \mathrm{NaOH}$ for 12 hours, to render the surface rough and increase its surface area for better adhesion of polymer and fibers. A study by Wang et al. revealed that $\mathrm{NaOH}$ treated and silane modified bamboo fiber-epoxy composite exhibited superior interfacial bonding. ${ }^{19}$ In addition, impregnation of the fibers with a compatibilizer helps in facilitating a chemical bond that prevents detrimental effects due to water sorption. In this study, impregnation in monomer (PMMA) and bonding agent (BAC) functioned as a compatibilizer to the resin matrix. According to the study by Fonseca et al. a better interaction between fibers and resin results in higher flexural strength. ${ }^{20}$

The fibers used in this study were in the form of rovings/ continuous form of length $22 \mathrm{~mm}$. In a study by Huang et al., the authors concluded that strip glass fibers showed better mechanical behavior than mesh fibers in fiber-reinforced resin composites. ${ }^{21}$ Takagi and Ichihara investigated the mechanical properties of bamboo fiber reinforced green composites and found that both tensile strength and flexural strength are strongly affected by fiber length and fiber content and the trend in increasing strength is saturated for fiber lengths over $15 \mathrm{~mm} .^{22}$ The bamboo fibers were incorporated longitudinally and laminated between the resin by layering and press molding technique. Placing fibers normally to the loading force has shown to provide the most effective reinforcement. Another method that can be used is the use of short fibers that are randomly oriented..$^{23}$ The ease and simplicity of their inclusion would make this technique more acceptable for widespread use, avoiding the necessity of interruption of packing procedures and time-consuming placement of oriented fibers or woven filaments. However, fiber incorporation by this technique will be affected by the viscosity of the material leading to the porosity of the matrix such as air bubble inclusions, pores, or voids. ${ }^{24}$

The quantity of the fibers to be added were decided based on a similar study done by previously on reinforcement of provisional restorative materials that found that the inclusion of dispersed glass fiber at more than $4 \%$ by weight seemed to show a plateau phenomenon in the flexural strength, up to $8 \%$ by weight. ${ }^{25}$ Excess of fibers beyond a point may prove detrimental to the mechanical property of the material due to improper adhesion of fiber and matrix.

The reinforced samples exhibited a greater flexural strength compared to the unreinforced samples. Among the reinforced samples highest flexural strength was shown by BAC resin. A balance between high mechanical strength, limited elasticity and low glass transition temperature of the BAC resin helps to withstand higher stresses until fracture and that can tolerate brief deformation.

The higher strength of BAC resins compared to PMMA can be attributed to the homogeneous mix provided a by auto-mixing cartridge of the base and catalyst whereas the PMMA resin is hand mixed. This study confirms the higher flexural strength of the control BAC resin as compared to PMMA resin. In a study by Alp et al., the flexural strength values of interim resin materials after thermocycling ranged between $66.1 \pm 13.1$ and $131.9 \pm 19.8 \mathrm{MPa}$ and BAC exhibited higher flexural strength compared to conventional PMMA. ${ }^{26}$ Nejatidanesh et al., also concluded that Bis-acrylic interim materials exhibited higher flexural strength compared to methacrylate resins. ${ }^{27}$ Similar results were obtained in studies by Young et al. $^{28}$ Traditional PMMA resins are monofunctional and have low molecular weight linear molecules that exhibit reduced strength and rigidity. In contrast, BAC resins are difunctional and have ability to cross-link with monomer chains; resulting in greater toughness and strength. The addition of bamboo fibers only further increased the flexural strength of both BAC resin and PMMA samples. Although many studies have investigated the flexural strength of PMMA and BAC, publications regarding reinforcement of these material with bamboo fibers is lacking. Therefore, direct comparison with other studies is not possible. An interesting feature that was noted upon testing was that the fractured components of the reinforced samples did not separate and rather remained intact with the help of the bamboo fiber. When using a reinforced provisional resin material clinically, it may be beneficial to choose a combination that, although fracturing, is held together by intact fibers. ${ }^{29}$

A strong material may often possess other less desirable characteristics such as tendency to stain, lack of polishability, difficult manipulation or poor esthetics. The only limitation for the use of bamboo fibers despite having a reinforcing effect is that it renders a brownish hue to the material, which might not be esthetically pleasing. The material has to be veneered to mask the brown color. Another limitation of the study is that we have evaluated only the flexural strength of the samples. It is important to note that flexural strength is only one of the behavior in response to a particular stress and it is just one property of provisional crown materials. Also, no cyclic loading in a moist environment or thermocycling of samples were performed. Further studies can be done to evaluate the effect on other mechanical properties such as fracture toughness and microhardness. Also, studies can be done to evaluate the effects of different concentration and orientation of the fibers on the mechanical properties.

\section{Conclusion}

Within the limitations of this study, bamboo fibers have a reinforcing effect on autopolymerizing Polymethyl methacrylate and Bis-acrylic composite provisional restorative resins and significantly increases their flexural strength. The methods incorporated in reinforcement of these materials with bamboo fibers have proven to be successful.

\section{References}

1. Mizrahi B. Temporary restorations: the key to success. Br Dent J 2019;226(10):761-768. DOI: 10.1038/s41415-019-0360-1.

2. Dureja I, Yadav B, Malhotra P, et al. A comparative evaluation of vertical marginal fit of provisional crowns fabricated by computeraided design/computer-aided manufacturing technique and direct (intraoral technique) and flexural strength of the materials: an in vitro study. J Indian Prosthodont Soc 2018;18(4):314-320. DOI: 10.4103/jips. jips_306_17.

3. Digholkar S, Madhav VN, Palaskar J. Evaluation of the flexural strength and microhardness of provisional crown and bridge materials fabricated by different methods. J Indian Prosthodont Soc 2016;16(4):328-334. DOI: 10.4103/0972-4052.191288.

4. Mei M, So S, Li H, et al. Effect of heat treatment on the physical properties of provisional crowns during polymerization: an in vitro study. Materials 2015;8(4):1766-1777. DOI: 10.3390/ma8041766.

5. Kapri A. Comparison of fiber reinforcement placed at different locations of pontic in interim fixed partial denture to prevent fracture: an in vitro study. J Indian Prosthodont Soc 2015;15(2):142. DOI: 10.4103/0972-4052.155037.

6. Gopichander N, Halini Kumarai KV, Vasanthakumar M. Effect of polyester fiber reinforcement on the mechanical properties of interim 
fixed partial dentures. Saudi Dent J 2015;27(4):194-200. DOI: 10.1016/j. sdentj.2015.03.002.

7. Mahir Fl, Keya KN, Sarker B, et al. A brief review on natural fiber used as a replacement of synthetic fiber in polymer composites. Mater Eng Res 2019;1(2):86-97. DOI: 10.25082/MER.2019.02.007.

8. Zhang K, Sun Y, Wang F, et al. Progressive failure and energy absorption of chopped bamboo fiber reinforced polybenzoxazine composite under impact loadings. Polymers (Basel) 2020;12(8):1809. DOI: 10.3390/polym12081809.

9. Zhang W, Wang C, Gu S, et al. Physical-mechanical properties of bamboo fiber composites using filament winding. Polymers (Basel) 2021;13(17):2913. DOI: 10.3390/polym13172913.

10. Lokesh P, Surya Kumari T, Gopi R, et al. A study on mechanical properties of bamboo fiber reinforced polymer composite. Mater Today: Proc 2020;22:897-903. DOI: 10.1016/j.matpr.2019.11.100.

11. Chin S, Tee K, Tong F, et al. Thermal and mechanical properties of bamboo fiber reinforced composites. Mater Today Commun 2020;23:100876. DOI: 10.1016/j.mtcomm.2019.100876.

12. Chang MC, Hung CC, Chen WC, et al. Effects of pontic span and fiber reinforcement on fracture strength of multi-unit provisional fixed partial dentures. J Dent Sci 2019;14(3):309-317. DOI: 10.1016/j. jds.2018.11.008

13. Psarri C, Kourtis S. Effect of fiber-reinforcement on the strength of polymer materials for provisional restorations: an in vitro study. J Esthet Restor Dent 2020;32(4):433-440. DOI: 10.1111/jerd.12586.

14. Gupt P, Nagpal A, Samra RK, et al. A comparative study to check fracture strength of provisional fixed partial dentures made of autopolymerizing polymethylmethacrylate resin reinforced with different materials: an in vitro study. J Indian Prosthodont Soc 2017;17(3):301-309. DOI: 10.4103/jips.jips_79_17.

15. Thyavihalli Girijappa YG, Mavinkere Rangappa S, Parameswaranpillai $J$, et al. Natural fibers as sustainable and renewable resource for development of eco-friendly composites: a comprehensive review. Front Mater 2019;6:226. DOI: 10.3389/fmats.2019.00226.

16. Qiu Z, Fan H. Nonlinear modeling of bamboo fiber reinforced composite materials. Compos Struct 2020;244:112240. DOI: 10.1016/j. compstruct.2020.112240.

17. Raghavendara Rao H, Hari Sankar P, Murali Mohan M. Chemical resistance and impact properties of bamboo/glass fibers reinforced polyster hybrid composites. Int J Engineer Res 2014;3(2):79-81. DOI: 10.17950/ijer/v3s2/209.
18. Zhang $K$, Wang F, Liang W, et al. Thermal and mechanical properties of bamboo fiber reinforced epoxy composites. Polymers 2018;10(6):608. DOI: $10.3390 /$ polym10060608.

19. Wang D, Bai T, Cheng W, et al. Surface modification of bamboo fibers to enhance the interfacial adhesion of epoxy resin-based composites prepared by resin transfer molding. Polymers (Basel) 2019;11(12):2107. DOI: 10.3390/polym11122107.

20. Fonseca R, Kasuya A, Favarão I, et al. The influence of polymerization type and reinforcement method on flexural strength of acrylic resin. Sci World J 2015. 1-8. DOI: 10.1155/2015/919142.

21. Huang $\mathrm{N}$, Bottino $\mathrm{M}$, Levon J, et al. The effect of polymerization methods and fiber types on the mechanical behavior of fiberreinforced resin-based composites. J Prosthodont 2017;26(3):230-237. DOI: 10.1111/jopr.12587.

22. Takagi $\mathrm{H}$, Ichihara Y. Effect of fiber length on mechanical properties of "green" composites using a starch-based resin and short bamboo fibers. JSME Int J 2004;47(4):551-555. DOI: 10.1299/jsmea. 47.551.

23. Tezvergil A, Lassila L, Vallittu P. The effect of fiber orientation on the polymerization shrinkage strain of fiber-reinforced composites. Dent Mater 2006;22(7):610-616. DOI: 10.1016/j.dental.2005.05.017.

24. Hamze F, Rezvani M, Atai M. Effect of fiber diameter on flexural properties of fiber-reinforced composites. Indian J Dent Res 2013;24(2):237. DOI: 10.4103/0970-9290.116696.

25. Chung K, Lin T, Wang F. Flexural strength of a provisional resin material with fibre addition. J Oral Rehabil 1998;25(3):214-217. DOI: 10.1046/j.1365-2842.1998.00201.x.

26. Alp G, Murat S, Yilmaz B. Comparison of flexural strength of different CAD/CAM PMMA-based polymers. J Prosthodont 2018;28(2):e491e495. DOI: 10.1111/jopr.12755.

27. Nejatidanesh F, Momeni G, Savabi O. Flexural strength of interim resin materials for fixed prosthodontics. J Prosthodont 2009;18(6):507-511. DOI: 10.1111/j.1532-849X.2009.00473.x.

28. Young $\mathrm{H}$, Smith $\mathrm{C}$, Morton D. Comparative in vitro evaluation of two provisional restorative materials. J Prosth Dent 2001;85(2):129-132. DOI: 10.1067/mpr.2001.112797.

29. Duymus ZY, Karaalioglu FO, Suleyman F. Flexural strength of provisional crown and fixed partial denture resins both with and without reinforced fiber. J Mater Sci Nanotechnol 2014;2(3):102. DOI: 10.15744/2348-9812.1.302. 
Flexural Strength of Bamboo Reinforced PMMA and BAC

\begin{tabular}{|c|c|c|c|c|c|c|c|c|}
\hline & Group I & $\begin{array}{l}\text { Unreinforced } \\
\text { PMMA }\end{array}$ & Group II & $\begin{array}{l}\text { Reinforced } \\
\text { PMMA }\end{array}$ & Group III & $\begin{array}{l}\text { Unreinforced } \\
B A C\end{array}$ & Group IV & $\begin{array}{l}\text { Reinforced } \\
B A C\end{array}$ \\
\hline Sample no. & $\begin{array}{l}\text { Fracture load } \\
(N)\end{array}$ & $\begin{array}{l}\text { Flexural } \\
\text { strength }(\mathrm{MPa})\end{array}$ & $\begin{array}{l}\text { Fracture load } \\
\text { (N) }\end{array}$ & $\begin{array}{l}\text { Flexural } \\
\text { strength }(\mathrm{MPa})\end{array}$ & $\begin{array}{l}\text { Fracture load } \\
\text { (N) }\end{array}$ & $\begin{array}{l}\text { Flexural } \\
\text { strength }(\mathrm{MPa})\end{array}$ & $\begin{array}{l}\text { Fracture load } \\
(N)\end{array}$ & $\begin{array}{l}\text { Flexural } \\
\text { strength }(\mathrm{MPa})\end{array}$ \\
\hline 1 & 50.62 & 94.91 & 50.62 & 94.91 & 54.98 & 103.08 & 87.98 & 164.96 \\
\hline 2 & 54.28 & 101.77 & 83.74 & 157.01 & 57.93 & 108.61 & 70.56 & 132.3 \\
\hline 3 & 64.13 & 120.24 & 74.19 & 139.1 & 61.11 & 114.58 & 66.03 & 123.8 \\
\hline 4 & 44.4 & 83.25 & 70.21 & 131.64 & 50.23 & 94.18 & 97.14 & 182.13 \\
\hline 5 & 51.19 & 95.98 & 55.29 & 103.66 & 52.7 & 98.81 & 59.21 & 111.01 \\
\hline 6 & 49.97 & 93.69 & 73.08 & 137.02 & 50 & 93.75 & 83.61 & 156.76 \\
\hline 7 & 40.15 & 75.28 & 30.15 & 56.53 & 47.76 & 89.55 & 98.27 & 184.25 \\
\hline 8 & 64.89 & 121.66 & 80.48 & 150.9 & 61.61 & 115.51 & 72.94 & 136.76 \\
\hline 9 & 53.19 & 99.73 & 33.19 & 62.23 & 54.52 & 102.22 & 66.5 & 124.68 \\
\hline 10 & 50.03 & 93.8 & 40.03 & 100.07 & 61.86 & 115.98 & 101 & 189.37 \\
\hline 11 & 50.66 & 94.98 & 107.59 & 201.73 & 50.66 & 94.98 & 91.86 & 172.23 \\
\hline 12 & 43.98 & 82.46 & 43.98 & 82.46 & 64.4 & 120.75 & 86.23 & 161.68 \\
\hline 13 & 59.2 & 111 & 96.08 & 180.15 & 59.2 & 111 & 75.79 & 142.1 \\
\hline 14 & 71.38 & 133.83 & 70.7 & 132.56 & 72.92 & 136.72 & 54.2 & 101.62 \\
\hline 15 & 46.26 & 86.73 & 94.99 & 178.1 & 54.48 & 102.15 & 108.12 & 202.72 \\
\hline Mean values & & 99.28 & & 127.2 & & 106.79 & & 152.42 \\
\hline
\end{tabular}

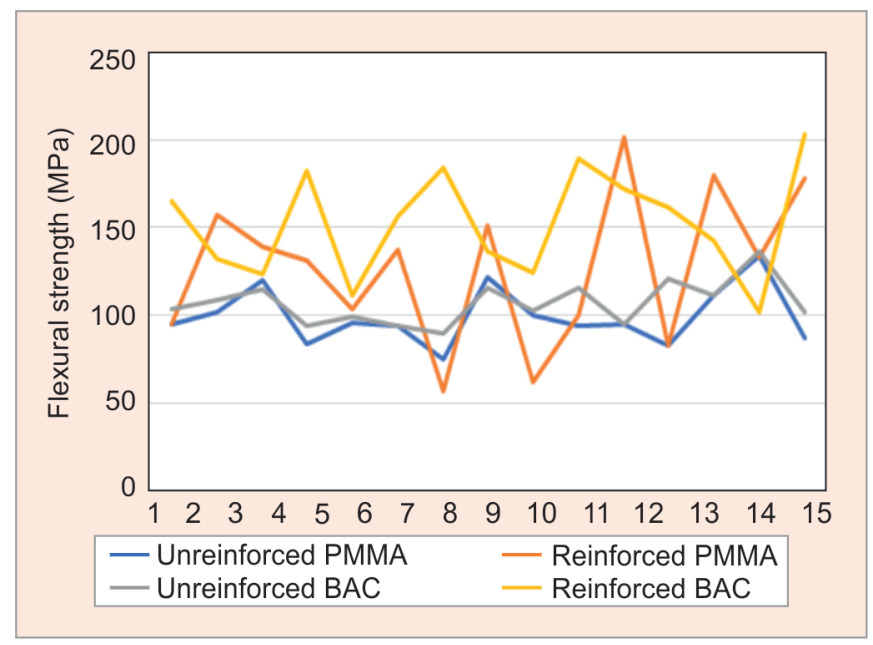

Supplementary Fig. 1: Flexural strength of the samples across all the groups 